24

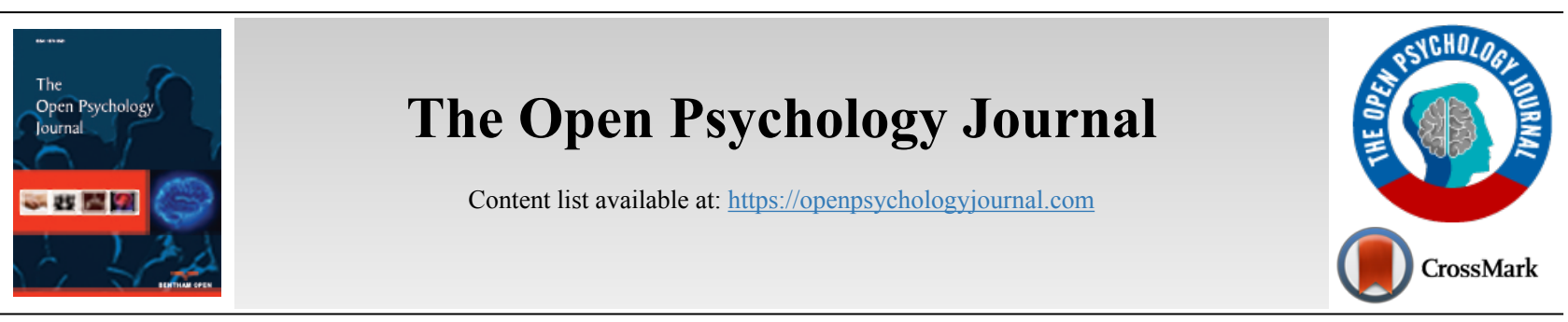

RESEARCH ARTICLE

\title{
Religious Fundamentalism between Traits and Values
}

\author{
Leonardo Carlucci ${ }^{1, *}$, Armin W. Geertz ${ }^{2}$, Laura Picconi ${ }^{1}$ and Michela Balsamo ${ }^{1}$ \\ ${ }^{I}$ School of Medicine and Health Sciences, "G. d'Annunzio” University of Chieti, Pescara, Italy \\ ${ }^{2}$ School of Culture and Society, Department of the Study of Religion, Aarhus University, Aarhus, Denmark
}

\begin{abstract}
:
Introduction:

Religious fundamentalism is a complex religious phenomenon that involves cultural and social domains. Like values, it would potentially provide a description of how human beings should be. Nevertheless, extensive research has focused on the association between traits and fundamentalism, while the link with values has so far been neglected.

\section{Methods:}

We examined how traits and values might predict religious fundamentalism in a sample of 250 Italian Catholics (57.5\% females).

Results:

Results partially confirmed the significant positive correlation between neuroticism and consciousness traits and religious fundamentalism, and highlighted the strong positive association with openness to change/conservative dimension value. In addition, when the overlap between traits and values was controlled for, hierarchical regression showed that values predicted fundamentalism better than traits.

Conclusion:

These findings could support the hypothesis that religious fundamentalism can be conceptualized as a motivational-goal attitude trait more than an enduring disposition.
\end{abstract}

Keywords: Religious fundamentalism, Values, Traits, Personality, Openness, Disposition.

\begin{tabular}{|l|l|l|l}
\hline Article History & Received: July 22, 2020 & Revised: September 24, 2020 & Accepted: November 02, 2020
\end{tabular}

\section{INTRODUCTION}

Religious fundamentalism embodies social, political, and psychological aspects. Different definitions of religious fundamentalism have been proposed in the literature [1 - 3]. In this study, we followed Altemeyer \& Hunsberger's definition of religious fundamentalism:

"The belief that there is one set of religious teaching that clearly contains the fundamental, basic, intrinsic, essential, inerrant truth about humanity and deity; that this essential truth is fundamentally opposed by evil forces which must be vigorously fought against. . . and those who believe and follow these fundamental teachings have a special relationship with deity." (p. 118) [1].

\footnotetext{
* Address correspondence to this author at the School of Medicine and Health Sciences, G. d'Annunzio University of Chieti-Pescara, Via dei Vestini, 31, 66100 Chieti, Italy; Tel +39 0871355 5310; Fax +39 0871355 5314;
}

E-maill.carlucci@unich.it
According to the dual component theory of religious fundamentalism $[4,5]$, two components are conceivable: 1$)$ an authoritarian structure that represents the way in which religious beliefs are held; and 2) a religious component that represents the content of the religious beliefs.

The coexistence of an authoritarian structure and a religious content belief has accounted for the religious fundamentalism paradox [6]. Prejudice [1, 7] and Christian orthodoxy [8] were found to be positively correlated with religious fundamentalism but negatively with each other. The dual component theory was also supported by Laythe and colleagues and Rowatt \& Franklin's studies [5, 9]. They found that when authoritarianism was partialled out, the relationship of religious fundamentalism was inversely related to prejudice.

A number of studies in the literature have been carried out to assess religious fundamentalism as specific religious experiences across cognitive, trait, and socio-cultural domains. 
Some have focused extensively on the relationship between religious fundamentalism and personality traits (see Saroglou's meta-analysis) [10], the need for cognitive closure and of low cognitive complexity [11], and authoritarianism and prejudice [12 - 15].

The relationship between values and religion, in general, has been examined extensively in the past using a variety of measures of global religiosity [16]. However, the term "religiosity" does not take into account the plurality and diversity of specific religious dimensions and their relationships with values [17]. To our knowledge, there are only a few studies in the literature focused on how values relate to specific religious domains [18], and specifically, two studies have been found to be concerned with religious fundamentalism $[19,20]$. This makes it difficult to compare similarities and differences between global religiosity and specific religious dimensions. Religiosity is conceived as a "quest" in contrast with conservation values, but privilege involves openness to change values, whereas extrinsic religion differs from intrinsic religion by the absence of the valorization of benevolence and by the valorization of power [21]. On the contrary, religious fundamentalism promotes values such as tradition, conformism and security, as well as ingroup prosociality attitudes over hedonistic and individual fulfillment values (i.e., achievement, self-direction) [14, 19].

An interesting datum that could reveal the difference between fundamentalism and global religiosity is the value of universalism [22]. Tarakeshwar and colleagues highlighted that religiosity does not correspond to pro-environmental attitudes and that religious fundamentalism is negatively related to these environmental attitudes [22].
Fundamentalist Christians in Finland were found to place the highest emphasis on the values of benevolence and universalistic concern. Societal security was also highly rated, but the mean score for the values of personal security and interpersonal conformity was lower than hypothesized. As expected, power and hedonism were rated very low [20]. In a sample of Italian Roman Catholics, religious fundamentalism scores correlated positively and highly with the values of tradition and conformity. Unlike the Finnish study, a weak association was found between religious fundamentalism and security and benevolence. Surprisingly, no correlation was found with the value of benevolence. On the contrary, hedonism, self-direction, stimulation, achievement and power correlated weakly with religious fundamentalism [19]. The most comprehensive theory of values was developed by Schwartz [23, 24], who defined values as "desirable goals, varying in importance, that serve as guiding principles in people's lives" (p. 21). Schwartz derived 10 different values (power, achievement, hedonism, stimulation, self-direction, universalism, benevolence, tradition, conformity and security), graphed in a circular manner (Fig. 1).

Values are arranged in opposite directions from the central point while matching values are in close proximity, emphasizing the conflict between values. The conflict and congruities among all the values yield an integrated structure composed of two orthogonal dimensions: (1) openness to change/conservation opposes self-direction and stimulation values to conformity, tradition and security values; and (2) selftranscendence/self-enhancement opposes universalism and benevolence values to achievement and power values. A unique exception is hedonism, which shares elements of both openness and self-enhancement.

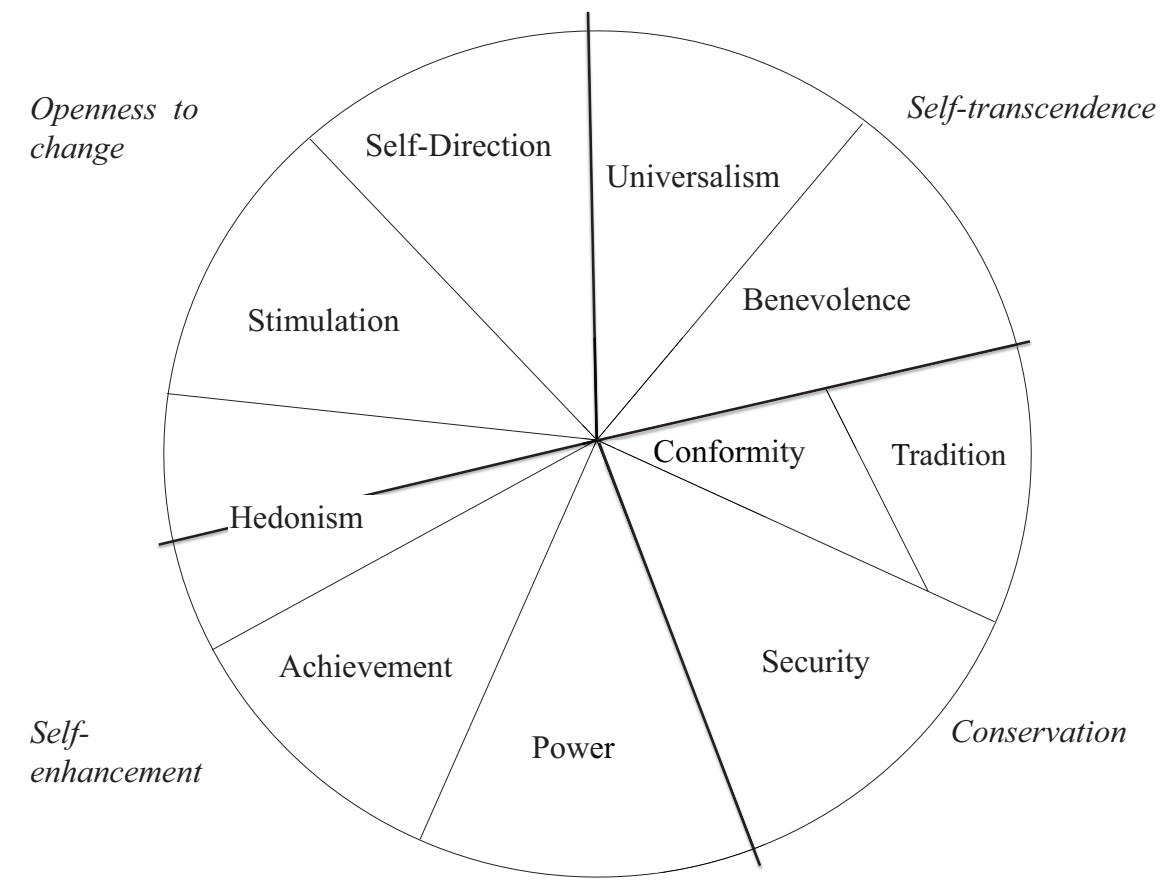

Fig. (1). Theoretical model of relations among 10 motivational types of values (Adapted from Schwartz [62], p. 9). 
Like personality traits, values drive human behaviour and shape human beliefs. Specifically, traits describe what people are like, whereas values denote what people consider important. Traits are enduring dispositions that vary in the frequency and intensity of their occurrence; values are enduring goals and vary in their importance in guiding people [25]. Both traits and values show different patterns of correlations with religiosity and spirituality, associated primarily with values but not traits $[18,25,26]$, and with positive effect associated primarily with traits but not values [27]. However, according to Lassander \& Nynäs, religious fundamentalism can be viewed as negotiations between personal values, religious subjectivities, and societal and contextual cultural behavioural influences [20].

Despite their distinctiveness, values and traits are broad categories of individual differences that are mutually influenced $[25,28]$. Indeed, people try to behave in line with their values [29]. A person with a specific personality trait could explain his/her behaviour by referring to his/her personal values. Both values and traits are used to justify choices or actions; but more often, values are used by people to judge themselves and others.

Many researchers conceive religious fundamentalism as a conformist personality trait $[10,30,31]$, associating it with a closed-minded personality dimension [32], a need for closure, and a preference for order and predictability [33]. On the other hand, it may be identified as a set of beliefs [1] related to social dimensions such as authoritarianism, prejudice and ethnocentrism, anti-modernist sociological phenomena [34], and an expression of socio-demographic variables [35].

The first aim of this study was to confirm the association between religious fundamentalism and values. In addition, we tried to replicate the association between traits and religious fundamentalism [19]. We expected that religious fundamentalism correlated strongly and positively with specific values that promote tradition, conformity and security [14], and negatively with values that destabilize the authoritarian fundamentalist structure (universalism, achievement, and power) [20]. With regard to traits, we expected to replicate the negative association between religious fundamentalism and the openness to experience trait [10, 30, 31].

Following the exploratory studies of Roccas et al. and Saroglou \& Muñoz-Garcia [18, 25], the second aim of this study was to replicate the hypothesis that personal values contribute to understanding fundamentalism more than personality dimensions. In performing hierarchical regression analysis, we hypothesized that personal values more than personality traits provide normative descriptions of how the world or human beings should be [36, 37].

\section{METHODS}

\subsection{Participants}

The sample included 250 religious Italian people $(42.5 \%$ males and $57.5 \%$ females). The mean age was 41.04 years (SD $=14.42$ ), and the range of age was $18-76$ years. The mean years of education of the sample were $14.15(\mathrm{SD}=3.25)$. All the participants defined themselves as Christian Roman
Catholics. The sample professed regular "church-attendance" $(\mathrm{M}=3.11, \mathrm{SD}=1.30)$ with a medium-high level of religiosity $(\mathrm{M}=4.39 ; \mathrm{SD}=1.74)$. For church attendance (how frequently people participate in worship), the scale ranged from 1 "once a day" to 6 "never". Their religiosity was assessed by a 7-point Likert scale from 1 "not religious" to 7 "very religious", as indicated by Schwartz and Huismans [38].

The tests were administered, after collecting informed consent from each participant, through visits by the researchers to the places of worship or through contacts with the clergy. The participants participated voluntarily and provided written informed consent. All questionnaires were anonymous and took approximately 15 minutes to be completed. The study protocol was reviewed and approved by the local research ethics review board, with the assurance that data would be reported anonymously and in aggregate form. All procedures were in accordance with the ethical standards of the 1964 Declaration of Helsinki and its later amendments.

\subsection{Measures}

The Portrait Values Questionnaire (PVQ) [39, 40], includes 40 short verbal portraits of different people, each describing an individual's wishes, purposes, or aspirations, that point implicitly to the importance of a value. Respondents judge how similar the person in the portrait is to themselves. For each item, ratings are on a 6-point Likert scale starting from 1 ("not at all similar to me") to 6 ("very similar to me"). Statements including "It is important for him to listen to people who are different from him", and "Even when he disagrees with them, he still wants to understand them" describe a person who holds universalism values as being important. Studies in seven countries supported the reliability of the PVQ for measuring the 10 values [40].

The shortened version of the Big Five Questionnaire (BFQ-S) [41], includes 60 items with the best psychometric properties from the original version of the BFQ [42]. These items form five domain scales (Openness [O], Consciousness $[\mathrm{C}]$, Extraversion [E], Agreeableness [A], Neuroticism [N]), according to the five-factor personality model [43]. The five domain scales are measured by 10 facet scales: Openness to experience and Openness to culture [O]; Scrupulousness and Perseverance $[\mathrm{C}]$; Dynamism and Dominance [E]; Cooperativeness and Politeness [E]; Emotion control and Impulse control [N], with six items on each scale. Respondents indicate agreement with the extent to which each item describes themselves, on a 5-point Likert scale ranging from 1 ("very false for me") to 5 ("very true for me"). The short form includes the items with the best psychometric properties from the original version of the BFQ [42]. Total scores were computed as the average of the items making up the facets scales.

The Religious Fundamentalism Scale (RFS [1],) is composed of 20 items, half of which are worded in co-trait direction to control for a response-set bias. The RFS scale is designed to measure a fundamentalist way of holding individuals' religious beliefs, and its items are free from doctrinal content. A brief version composed of 12 statements has been derived from the full-length scale (RFS-12) [7, 44]; 
with the same characteristics. For each item, ratings are on a 9point Likert scale starting from -4 ("you strongly disagree") to +4 ("you strongly agree"). Examples of items include "No single book of religious teachings contains all the intrinsic, fundamental truths about life", and "When you get right down to it, there are basically only two kinds of people in the world: the Righteous, who will be rewarded by God, and the rest, who will not". Total scores ranged from 20 to 120 , with a midpoint equal to 100 . High scores on this scale are associated with high levels of religious fundamentalism.

\subsection{Statistical Analyses}

Descriptive statistics and reliability were calculated for all the questionnaires involved in the study. Partial correlations were computed in order to clarify the role of age and education in the relationships between values, traits and religious fundamentalism (i.e., the first aim). Both age and education were found to have a strong effect on religiousness and fundamentalism [45]. Empirical findings suggested an overall aging effect in religious intensity and strength of beliefs over the adult lifespan [45 - 47]. Equally, low levels of education consistently predicted fundamentalists' beliefs promoting conformity and tradition $[19,45,48]$. The same effects were found between background variables (age, education) and values /personality traits [39].

To pursue the second aim, following Roccas et al. [25] and Saroglou \& Muñoz-Garcia [18] concerning the impact of traits and values domains on RFS, we used hierarchical regression, with Bonferroni correction, controlling for age and education. We used the ten BFQ facets rather than the five domain scales in order to provide common metrics to measure values and personality traits for comparing their predictive power. In the statistical analyses, the value data were controlled for individual differences by centering responses to each item, as recommended by Schwartz [23].

\section{RESULTS}

In order to test the relationships between traits, values and fundamentalism, we performed partial correlations, controlling for age and education (Table 1). The religious fundamentalism scale measure was positively correlated with emotion control $(r$ $=.13, \mathrm{p}<.05)$ and impulse control $(r=.14, \mathrm{p}<.05)$. In addition, the religious fundamentalism scale correlated positively with the politeness facets scale of agreeableness ( $r=$ $.15, \mathrm{p}<.05)$. Surprisingly, no significant difference was found between fundamentalism and openness facets, probably due to the age-education partialized effect.

Table 1. Descriptive statistics, reliabilities and partial correlations for BFQ, PVQ and RFS ( $N=250)$.

\begin{tabular}{|c|c|c|c|c|c|c|c|c|c|c|c|c|c|c|c|c|c|c|c|c|c|}
\hline & & \multicolumn{10}{|c|}{ Schwartz values } & \multicolumn{10}{|c|}{ Personality facets } \\
\hline & RFS & $\mathrm{CO}$ & TR & $\mathrm{BE}$ & UN & SD & ST & $\mathrm{HE}$ & $\mathrm{AC}$ & PO & SE & Dy & Do & $\mathrm{Sc}$ & $\mathrm{Pe}$ & $\mathrm{EC}$ & IC & Co & Po & $\mathrm{OC}$ & $\mathrm{OE}$ \\
\hline RFS & & $.26 * *$ & $.45 * *$ & $.15^{*}$ & -.02 & $-.22 * *$ & $-.20 * *$ & $-.26 * *$ & $-.19 * *$ & $-.13 *$ & $.14 *$ & .06 & -.06 & .05 & .07 & $.13 *$ & $.14 *$ & -.01 & $.15^{*}$ & -.08 & -.10 \\
\hline $\mathrm{CO}$ & & & $.33 * *$ & $.21 * *$ & $.17 *$ & $-.36 * *$ & \begin{tabular}{|l|}
-.50 \\
\end{tabular} & -.48 & -.35 & $-.37 * *$ & $.27 * *$ & -.10 & $-.28 * *$ & .02 & -.10 & .06 & $.23 * *$ & .08 & $21^{* *}$ & $-.14 *$ & $-.26 * *$ \\
\hline $\mathrm{TR}$ & & & & $.34 * *$ & $.25 * *$ & $-.27 * *$ & $-.47 * *$ & $-.43 * *$ & $-.51 * *$ & $-.40 * *$ & .10 & -.11 & $-.49 * *$ & $-.13 *$ & $-.22 * *$ & -.07 & $21 * *$ & .09 & $.22 * *$ & \begin{tabular}{|l|}
-.11 \\
\end{tabular} & $-.30 * *$ \\
\hline $\mathrm{BE}$ & & & & & $.56 * *$ & -.05 & $-.31 * *$ & $-.45 * *$ & $-.58 * *$ & $-.62 * *$ & \begin{tabular}{|l|}
$-.17^{*}$ \\
\end{tabular} & .12 & $-.51 * *$ & .00 & $-.18^{*}$ & -.04 & .26 & $.50 * *$ & $.56 * *$ & $.20^{*}$ & .12 \\
\hline $\mathrm{UN}$ & & & & & & -.03 & $-.34 * *$ & $-.46 * *$ & $-.64 * *$ & $-.65 * *$ & \begin{tabular}{|l|}
-.06 \\
\end{tabular} & -.03 & $-.58 * *$ & \begin{tabular}{|l|}
-.07 \\
\end{tabular} & $-.17 *$ & .01 & $.29 * *$ & $.36 * *$ & $.47 * *$ & $.16^{*}$ & .00 \\
\hline SD & & & & & & & $.27 * *$ & \begin{tabular}{|l|}
.05 \\
\end{tabular} & \begin{tabular}{|l|l|}
-.05 \\
\end{tabular} & \begin{tabular}{|l|}
-.03 \\
\end{tabular} & $-.26 * *$ & .08 & \begin{tabular}{|l|}
.11 \\
\end{tabular} & .07 & .05 & .08 & \begin{tabular}{|l|}
-.03 \\
\end{tabular} & \begin{tabular}{l|}
.04 \\
\end{tabular} & -.10 & $.17^{*}$ & .27 \\
\hline ST & & & & & & & & $.48^{* *}$ & $.27 * *$ & \begin{tabular}{|l|l|} 
\\
\end{tabular} & \begin{tabular}{|l|l|}
$-.46^{* *}$ \\
\end{tabular} & $.16^{*}$ & \begin{tabular}{|l|}
$.33 * *$ \\
\end{tabular} & .00 & .20 & .01 & $-.22 * *$ & -.14 & $-.24 * *$ & .04 & \begin{tabular}{|l|}
$.36^{* *}$ \\
\end{tabular} \\
\hline $\mathrm{HE}$ & & & & & & & & & $.32 * *$ & $.31 * *$ & \begin{tabular}{|l|}
$-.17^{*}$ \\
\end{tabular} & .05 & $.33 * *$ & \begin{tabular}{|l|}
-.07 \\
\end{tabular} & .11 & .05 & $-.20^{*}$ & $-.17 *$ & $-.32 * *$ & \begin{tabular}{|l|}
-.02 \\
\end{tabular} & $.19 *$ \\
\hline $\mathrm{AC}$ & & & & & & & & & & $.65 * *$ & \begin{tabular}{|l|}
$-.16^{*}$ \\
\end{tabular} & .04 & $.62 * *$ & .12 & $.23 * *$ & -.09 & $-.37 * *$ & $-.30 * *$ & $-.33 * *$ & \begin{tabular}{|l|}
-.06 \\
\end{tabular} & .07 \\
\hline $\mathrm{PO}$ & & & & & & & & & & & \begin{tabular}{|l|}
$-.18^{*}$ \\
\end{tabular} & -.04 & $.61 * *$ & \begin{tabular}{|l|}
-.01 \\
\end{tabular} & .13 & .02 & $-.28 * *$ & $-.33 * *$ & \begin{tabular}{|l|}
$-.40 * *$ \\
\end{tabular} & \begin{tabular}{|l|}
-.12 \\
\end{tabular} & .01 \\
\hline $\mathrm{SE}$ & & & & & & & & & & & & $-.13^{*}$ & \begin{tabular}{|l|}
-.08 \\
\end{tabular} & .08 & -.01 & .00 & \begin{tabular}{|l|}
.08 \\
\end{tabular} & $-.16^{*}$ & $-.16^{*}$ & \begin{tabular}{|l|}
-.09 \\
\end{tabular} & $-.36^{* *}$ \\
\hline Dy & & & & & & & & & & & & & $.21 * *$ & $.27 * *$ & $.41 * *$ & $.20 *$ & -.04 & $.32 * *$ & \begin{tabular}{|l|}
$.20 * *$ \\
\end{tabular} & \begin{tabular}{|l|}
$.22 * *$ \\
\end{tabular} & $.42 * *$ \\
\hline Do & & & & & & & & & & & & & & $.25 * *$ & $.30 * *$ & .01 & $-.38 * *$ & $-.27 * *$ & $-.39 * *$ & \begin{tabular}{|l|}
-.03 \\
\end{tabular} & $.20 *$ \\
\hline $\mathrm{Sc}$ & & & & & & & & & & & & & & & $.38 * *$ & \begin{tabular}{|l|}
-.09 \\
\end{tabular} & \begin{tabular}{|l|}
-.04 \\
\end{tabular} & $.14 *$ & \begin{tabular}{|l|}
.03 \\
\end{tabular} & $.20 * *$ & $.19 *$ \\
\hline $\mathrm{Pe}$ & & & & & & & & & & & & & & & & $.20 * *$ & -.05 & .10 & -.05 & $.16^{*}$ & $.24 * *$ \\
\hline $\mathrm{EC}$ & & & & & & & & & & & & & & & & & $.54 * *$ & .07 & .11 & .05 & .09 \\
\hline IC & & & & & & & & & & & & & & & & & & $.19 *$ & $37 * *$ & .03 & -.06 \\
\hline Co & & & & & & & & & & & & & & & & & & & $.53 * *$ & $.36 * *$ & $.31 * *$ \\
\hline Po & & & & & & & & & & & & & & & & & & & & $.23 * *$ & \begin{tabular}{|l|l|}
$.18^{*}$ \\
\end{tabular} \\
\hline $\mathrm{OC}$ & & & & & & & & & & & & & & & & & & & & & $.39 * *$ \\
\hline $\mathrm{OE}$ & & & & & & & & & & & & & & & & & & & & & \\
\hline$M$ & 89.4 & 4.34 & 3.97 & 4.57 & 4.77 & 4.57 & 3.63 & 3.7 & 3.56 & 2.87 & 4.47 & 3.5 & 2.77 & 3.51 & 3.56 & 2.89 & 2.95 & 3.51 & 3.23 & 3.52 & 3.44 \\
\hline$S D$ & 27.63 & 0.88 & 0.84 & 0.84 & 0.74 & 0.76 & 1.02 & 1.17 & 1.1 & 1.17 & 0.86 & 0.68 & 0.72 & 0.69 & 0.62 & 0.8 & 0.81 & 0.57 & 0.66 & 0.74 & 0.65 \\
\hline$\alpha$ & \begin{tabular}{|l|l|}
0.88 \\
\end{tabular} & 0.64 & \begin{tabular}{l|l|}
0.57 \\
\end{tabular} & 0.71 & 0.74 & 0.57 & 0.64 & 0.79 & 0.79 & 0.79 & 0.72 & \begin{tabular}{|l|l|}
0.71 \\
\end{tabular} & 0.70 & 0.70 & 0.65 & \begin{tabular}{|l|l|}
0.76 \\
\end{tabular} & 0.78 & 0.56 & 0.65 & 0.72 & 0.68 \\
\hline
\end{tabular}


No significant correlations were found between the religious fundamentalism scale, consciousness and extraversion traits. In addition, religious people who scored high on the religious fundamentalism scale tended to be kind, civil and trusting towards others and their needs [14]. They were able to control proper emotional and impulsive reactions, but were low in exploration of novelty and tolerance of diversity $[1,5,12$, 49]. With regard to values, religious fundamentalism showed positive correlations with tradition $(r=.45, \mathrm{p}<.01)$, conformity $(r=.26, \mathrm{p}<.01)$, benevolence $(r=.15, \mathrm{p}<.05)$, and security $(r=.14, \mathrm{p}<.05)$. Negative associations were found with hedonism $(r=-.26, \mathrm{p}<.01)$, self-direction $(r=-.22$, $\mathrm{p}<.01)$, stimulation $(r=-.20, \mathrm{p}<.01)$, achievement $(r=-.19$, $\mathrm{p}<.01)$, and power $(r=-.13, \mathrm{p}<.05)$. In line with the comparative religion literature $[16,38,50]$, the religious content of fundamentalism was associated with high importance attributed to tradition, conformity, benevolence and security $[19,20]$. Low importance was attributed to hedonism, self-direction, stimulations and achievement. Fundamentalistic people at the same time firmly held certain beliefs and values, that is, conservation of the social order and prosocial values (except universalism), therefore de-emphasizing autonomy and hedonism.

In order to pursue the second aim of this study (i.e., personal values contribute to understanding religious fundamentalism more than personality dimensions), two series of hierarchical regression analyses were carried out. In each series, religious fundamentalism was entered each time as the predicted variable controlled by age and years of education. In the first series (Model 1), age and education (sociodemographic block), the 10 personality facets (BFQ block) and then the 10 values (PVQ block) were entered as predictors of the fundamentalism variable. In the second series, (Model 2) the Socio-demographic block, first the PVQ block and then the BFQ block were entered. The goal of Model 1 was to test whether the PVQ added any value once the variance explained by Big Five traits was partialled out of fundamentalism as a dependent variable. Conversely, in Model 2, the influence of the Big Five traits on RFS was tested. Table 2 details the incremental variance $\left(\mathrm{R}^{2}\right)$ and the Adjusted $\mathrm{R}^{2}\left(\operatorname{Adj} . \mathrm{R}^{2}\right)$ in religious fundamentalism accounted for in each step of each model. In Model 1, the PVQ block $\left(\mathrm{R}^{2}=.229, \mathrm{p}<.01\right)$ provided a significant increment in the $\mathrm{R}^{2}$ after the Big Five traits block $\left(\mathrm{R}^{2}=.069, \mathrm{p}<.01\right)$ was partialled out. In Model 2, the Big Five traits block $\left(\mathrm{R}^{2}=.066\right.$, n.s. $)$ confirmed the small, not significant, increment when the PVQ block $\left(\mathrm{R}^{2}=.232 \mathrm{p}<\right.$ $.01)$ was partialled out. Regression coefficients and the significance of each PVQ and BFQ dimensions are displayed in Appendix A.

\section{DISCUSSION}

This study, firstly, sought to examine the relations between values and traits in religious fundamentalism in order to clarify some issues regarding the nature of religious fundamentalism. Correlations revealed that conformity, tradition and security values provided an increased association with fundamentalism. It is well documented that believers with a high personal mindset towards dependence on and submission to authority need to refer to religious traditions (beliefs and practices) and authorities as indispensable sources legitimizing their behaviours and emotions [17]. In the same manner, traditional values express the motivation to maintain the customs, traditions, and hierarchy of one's social groups. Not surprisingly, both conformity and tradition were found to be positively related to the cooperative aspect of agreeableness $[25,51]$.

These correlation patterns may represent a sort of protective mechanism, which safeguards the fundamentalist against ambiguity. Not surprisingly, fundamentalistic believers have been found to be marginally prone to anxiety resulting from questioning one's belief system (the doubt syndrome) [52]. Adherence to doctrinal beliefs allows for a reduction of cognitive uncertainty, to deal with confusion, and to reduce existential anxiety [11]. High levels of uncertainty and reactivity experienced by fundamentalists were found to have important implications for personality and identity development [53].

Table 2. Incremental variance in the RF measure accounted for in hierarchical regression analyses $(N=\mathbf{2 5 0})$.

\begin{tabular}{|c|c|c|}
\hline Predictor & \multicolumn{2}{|c|}{$\begin{array}{c}\text { Religious } \\
\text { Fundamentalism }\end{array}$} \\
\hline Model 1 & $\begin{array}{c}\text { Incremental } \\
\text {-squared }\end{array}$ & ${\text { Adj. } \mathrm{R}^{2}}$ \\
\hline Socio-demographic block & & .121 \\
\hline BFQ block & $.069^{\text {ns }}$ & .156 \\
\hline PVQ block & $.229^{* *}$ & .372 \\
\hline Model 2 & & $128^{* *}$ \\
\hline Socio-demographic block & $.232^{* *}$ & .121 \\
\hline PVQ block & $.066^{\text {ns }}$ & .330 \\
\hline BFQ block & & .372 \\
\hline
\end{tabular}


Appendix A. Summary of hierarchical regression of Model 1 and 2 for variables predicting, in turn, religious fundamentalism.

\begin{tabular}{|c|c|c|c|c|c|c|c|c|c|c|c|c|c|}
\hline & & \multicolumn{2}{|c|}{ MODEL 1} & \multirow[b]{2}{*}{$\boldsymbol{\beta}$} & \multirow[b]{2}{*}{$t$} & \multirow[b]{2}{*}{$p$} & & & \multirow[b]{2}{*}{ B } & \multirow{2}{*}{$\begin{array}{c}\text { MODEL 2 } \\
\text { SE } \\
\end{array}$} & \multirow[b]{2}{*}{$\boldsymbol{\beta}$} & \multirow[b]{2}{*}{$t$} & \multirow[b]{2}{*}{$p$} \\
\hline \multicolumn{2}{|r|}{ Step } & B & SE & & & & & Step & & & & & \\
\hline \multirow[t]{2}{*}{$1 \mathrm{a}$} & Age & .023 & .006 & .239 & 3.956 & .000 & \multirow[t]{2}{*}{$1 \mathrm{a}$} & Age & .023 & .006 & .239 & 3.956 & .000 \\
\hline & Education & -.214 & .056 & -.232 & -3.844 & .000 & & Education & -.214 & .056 & -.232 & -3.844 & .000 \\
\hline \multirow[t]{12}{*}{$2 b$} & Age & .017 & .006 & .176 & 2.749 & .006 & \multirow[t]{11}{*}{$2 b$} & Age & .005 & .006 & .058 & .961 & .338 \\
\hline & Education & -.183 & .057 & -.199 & -3.188 & .002 & & Education & -.115 & .051 & -.125 & -2.256 & .025 \\
\hline & Dy & .117 & .148 & .059 & .794 & .428 & & $\mathrm{CO}$ & .172 & .159 & .093 & 1.078 & .282 \\
\hline & Do & -.037 & .144 & -.020 & -.255 & .799 & & $\mathrm{TR}$ & .711 & .136 & .424 & 5.234 & .000 \\
\hline & $\mathrm{Sc}$ & .126 & .134 & .065 & .943 & .347 & & $\mathrm{BE}$ & .184 & .162 & .102 & 1.135 & .257 \\
\hline & $\mathrm{Pe}$ & .146 & .156 & .066 & .934 & .351 & & $\mathrm{UN}$ & -.376 & .192 & -.189 & -1.961 & .051 \\
\hline & $\mathrm{EC}$ & .169 & .134 & .100 & 1.259 & .209 & & $\mathrm{SD}$ & -.165 & .160 & -.075 & -1.027 & .306 \\
\hline & $\mathrm{IC}$ & .009 & .142 & .005 & .062 & .951 & & ST & .205 & .135 & .137 & 1.523 & .129 \\
\hline & Co & -.266 & .183 & -.112 & -1.454 & .147 & & $\mathrm{HE}$ & -.165 & .126 & -.127 & -1.311 & .191 \\
\hline & Po & .392 & .162 & .190 & 2.421 & .016 & & $\mathrm{PO}$ & .061 & .149 & .050 & .412 & .680 \\
\hline & $\mathrm{OC}$ & -.141 & .128 & -.077 & -1.104 & .271 & & SE & .226 & .182 & .113 & 1.242 & .215 \\
\hline & $\mathrm{OE}$ & -.301 & .152 & -.145 & -1.973 & .050 & \multirow[t]{21}{*}{$3 c$} & Age & .002 & .006 & .023 & .372 & .710 \\
\hline \multirow[t]{22}{*}{$3 \mathrm{c}$} & Age & .002 & .006 & .023 & .372 & .710 & & Education & -.095 & .052 & -.104 & -1.837 & .068 \\
\hline & Education & -.095 & .052 & -.104 & -1.837 & .068 & & $\mathrm{CO}$ & .172 & .161 & .093 & 1.070 & .286 \\
\hline & Dy & -.043 & .130 & -.021 & -.327 & .744 & & TR & .881 & .144 & .526 & 6.123 & .000 \\
\hline & Do & .333 & .154 & .178 & 2.162 & .032 & & $\mathrm{BE}$ & .302 & .171 & .169 & 1.764 & .079 \\
\hline & $\mathrm{Sc}$ & .067 & .119 & .035 & .567 & .571 & & $\mathrm{UN}$ & -.220 & .201 & -.110 & -1.095 & .275 \\
\hline & $\mathrm{Pe}$ & .209 & .138 & .095 & 1.509 & .133 & & SD & -.134 & .163 & -.061 & -.822 & .412 \\
\hline & $\mathrm{EC}$ & .275 & .118 & .163 & 2.338 & .020 & & ST & .220 & .135 & .147 & 1.631 & .104 \\
\hline & IC & -.077 & .123 & -.046 & -.628 & .531 & & $\mathrm{HE}$ & -.099 & .128 & -.076 & -.773 & .440 \\
\hline & Co & -.273 & .164 & -.115 & -1.663 & .098 & & $\mathrm{PO}$ & .052 & .150 & .042 & .347 & .729 \\
\hline & Po & .272 & .152 & .132 & 1.784 & .076 & & SE & .315 & .185 & .157 & 1.702 & .090 \\
\hline & $\mathrm{OC}$ & -.048 & .113 & -.026 & -.427 & .670 & & Dy & -.043 & .130 & -.021 & -.327 & .744 \\
\hline & $\mathrm{OE}$ & .041 & .146 & .020 & .282 & .778 & & Do & .333 & .154 & .178 & 2.162 & .032 \\
\hline & $\mathrm{CO}$ & .172 & .161 & .093 & 1.070 & .286 & & $\mathrm{Sc}$ & .067 & .119 & .035 & .567 & .571 \\
\hline & TR & .881 & .144 & .526 & 6.123 & .000 & & $\mathrm{Pe}$ & .209 & .138 & .095 & 1.509 & .133 \\
\hline & $\mathrm{BE}$ & .302 & .171 & .169 & 1.764 & .079 & & $\mathrm{EC}$ & .275 & .118 & .163 & 2.338 & .020 \\
\hline & UN & -.220 & .201 & -.110 & -1.095 & .275 & & IC & -.077 & .123 & -.046 & -.628 & .531 \\
\hline & SD & -.134 & .163 & -.061 & -.822 & .412 & & Co & -.273 & .164 & -.115 & -1.663 & .098 \\
\hline & ST & .220 & .135 & .147 & 1.631 & .104 & & Po & .272 & .152 & .132 & 1.784 & .076 \\
\hline & $\mathrm{HE}$ & -.099 & .128 & -.076 & -.773 & .440 & & $\mathrm{OC}$ & -.048 & .113 & -.026 & -.427 & .670 \\
\hline & $\mathrm{PO}$ & .052 & .150 & .042 & .347 & .729 & & $\mathrm{OE}$ & .041 & .146 & .020 & .282 & .778 \\
\hline & SE & .315 & .185 & .157 & 1.702 & .090 & & Models fit & & & & & \\
\hline & Models fit & & & & & & $\mathrm{a}$ & $\mathrm{R}=.358$ & $\mathrm{R}^{2}=.128$ & $\mathrm{R}^{2} \mathrm{adj} .=.121$ & & & \\
\hline $\mathrm{a}$ & $\mathrm{R}=.358$ & $\mathrm{R}^{2}=.128$ & $\mathrm{R}^{2} \mathrm{adj} .=.121$ & & & & $\mathrm{~b}$ & $\mathrm{R}=.600$ & $\mathrm{R}^{2}=.360$ & $\mathrm{R}^{2}$ adj. $=.330$ & & & \\
\hline $\mathrm{b}$ & $\mathrm{R}=.444$ & $\mathrm{R}^{2}=.197$ & $\mathrm{R}^{2}$ adj. $=.156$ & & & & $\mathrm{c}$ & $\mathrm{R}=.653$ & $\mathrm{R}^{2}=.426$ & $\mathrm{R}^{2}$ adj. $=.372$ & & & \\
\hline $\mathrm{c}$ & $\mathrm{R}=.653$ & $\mathrm{R}^{2}=.426$ & $\mathrm{R}^{2}$ adj. $=.372$ & & & & & & & & & & \\
\hline
\end{tabular}

Note

$\mathrm{CO}=$ Conformity $\mathrm{TR}=$ Tradition; $\mathrm{BE}=$ Benevolence $\mathrm{UN}=$ Universalism; $\mathrm{SD}=$ Self-direction; $\mathrm{ST}=\mathrm{Stimulation} ; \mathrm{HE}=\mathrm{Hedonism} ; \mathrm{PO}=\mathrm{Power} ; \mathrm{SE}=\mathrm{Security} ; \mathrm{Dy}=$ Dynamism; $\mathrm{Do}=$ Dominance; $\mathrm{Sc}=$ Scrupulousness; $\mathrm{Pe}=$ Perseverance; $\mathrm{EC}=$ Emotion Control; $\mathrm{IC}=\mathrm{Impulse} \mathrm{Control} ; \mathrm{Co}=\mathrm{Cooperativeness} ; \mathrm{Po}=\mathrm{Politeness} ; \mathrm{OC}=\mathrm{Openness}$ to Culture; $\mathrm{OE}=$ Openness to Experience.

Bold font indicates statistical significance values $(\mathrm{p}<.05)$

Tradition, with regard to acceptance of the customs and ideas that religion provides, represents the value best associated with religious fundamentalism, more than conformity and security [19]. A remarkable aspect of religious fundamentalism is the positive association with benevolence but not with universalism. This finding supports the in-group prosociality attitude in line with previous studies found in the literature [14]. The benevolence value has been conceptualized as the preservation and enhancement of the welfare of people with whom one is in frequent personal contact, whereas universalism concerns the welfare of all people and nature [38]. The association between religious fundamentalism and values that emphasize openness to change, like novelty, challenge in life (stimulation), and explorative and independent thought and 
action choices (self-direction) was lower [19, 20, 38].

Correlations confirm part of the relationship between traits and religious fundamentalism found in the literature [10, 53, 54]. Emotional stability and politeness facets of the BFQ correlated positively with religious fundamentalism. The link with the openness domain, extensively reported in the literature $[31,54]$, was not confirmed in this study. This can be due to the age-education moderation effect since our sample was mainly composed of young, old and well educated. As highlighted in the study by Carlucci et al. [45], years of education (less educated) and age (older adults) were found respectively to play a direct and indirect role in religious fundamentalism.

These findings, in part, are in line with the previous literature showing that emotional stability facets [45] and agreeableness domain are personality traits related to religious fundamentalism, and this holds true across different cultures, religions, and cohorts [10].

\section{CONCLUSION}

Summarizing, our findings highlighted the association between religious fundamentalism and openness to change/conservative dimension and emotional stability trait. In particular, the great effects observed of tradition, conformity and security on religious fundamentalism draw attention to anxiety control versus growth and self-expansion values and principles [24]. In other words, fundamentalists seek to avoid threats (conformity) and preserve the status quo (tradition, security) through emotion and impulse control (emotional stability facets) and in-group pro-sociality behaviors (benevolence and politeness trait). Similar to a homeostatic process, this anxiety mechanism regulates avoidance of punishment, makes people focus on the goal of preventing loss, regulates pursuit of rewards, and makes people focus on the goal of promoting gain $[24,55]$.

The second aim of the study was to measure the contribution that personality traits and personal values provide to predicting religious fundamentalism. We hypothesized that values provided a major contribution to understanding religious fundamentalism, compared to traits. A cultural adaptation variable seems to predict religious fundamentalism better than personality traits. In particular, values explained a great part of religious fundamentalism variance in our hierarchical regression analysis.

Religious fundamentalism, similar to values, may concern the evaluation and justification of choices and actions. Strong religious believers characterized by a strong need for cognitive closure tend to minimise the amount of cognitive work used in making decisions (a fundamentalist attitude [56]). In religious people, goal-driven behaviours were found to operate under at least partial cognitive control [25], rather than a set of predispositions to certain behaviours. This, in part, can explain the "parental transmission" hypothesis and the "conversion" hypothesis which involve how people decide to convert to a fundamentalist religion [13]. Conversion processes promote changes (cognitive reframing) in terms of goals, purposes, values and identity dimensions $[57,58]$, leading to a new meaning system [57] and not to a personality traits level. At the same time, shared family environment, familial religious education and religious socialization represent carriers of strong values. Following Roccas and colleagues [25], traits may affect more strongly behaviours and tendencies subject to minimal cognitive control, while values may influence more strongly behaviours and attitudes that are under more voluntary control.

Our results suggest that religious fundamentalism represents how individual differences are closer to values than to traits when socio-demographic variables are mediators. More than traits, values promote a conservative attitude that reinforces fundamentalistic beliefs. Our findings replicate previous research carried out on the role of values and traits in religiousness and spirituality $[18,25]$ and have extended it to religious fundamentalism.

This study has several limitations. A particular sample from a specific culture and religion (i.e., Italian Roman Catholics in the present study) could influence the generalizability of our results. In addition, the cross-sectional nature of the present study makes it susceptible to biases such as responder bias, and because the exposure and outcome are simultaneously assessed, there is generally no evidence of a causal relationship between them [59, 60]. In addition, the extensive use of self-report measures to assess religious phenomena is biased by both intentional and unintentional distortions. Paper-and-pencil measures may be limited when studying religion and spirituality due to the importance of religious beliefs and practices, which are evidently difficult to detect through self-statements (for example, persons may feel a social pressure to affirm certain religious beliefs) [61]. Further studies are necessary to discern the role of values and traits in religious fundamentalism, using different methodologies and instruments.

\section{ETHICS APPROVAL AND CONSENT TO PARTICIPATE}

The study was approved by the review board of the Department of Psychological Sciences, Health and Territory, University of Chieti, Italy.

\section{HUMAN AND ANIMAL RIGHTS}

No animals were used in this study. All human procedures were followed in accordance with the ethical standards of the 1964 Declaration of Helsinki and its later amendments.

\section{CONSENT FOR PUBLICATION}

The participants participated voluntarily and provided written informed consent.

\section{AVAILABILITY OF DATA AND MATERIALS}

The data and materials used to support the findings of this study are available from the corresponding author (L.C) upon reasonable request.

\section{FUNDING}

None. 


\section{CONFLICT OF INTEREST}

The authors declare no conflict of interest, financial or otherwise.

\section{ACKNOWLEDGEMENTS}

Declared none.

\section{REFERENCES}

[1] Altemeyer B, Hunsberger B. Authoritarianism, religious fundamentalism, quest, and prejudice. Int J Psychol Relig 1992; 2(2): 113-33.

[http://dx.doi.org/10.1207/s15327582ijpr0202_5]

[2] Hood RW Jr, Hill PC, Spilka B. The Psychology of Religion: An Empirical Approach. New York: Guilford Publications 2018.

[3] Liht J, Conway LG, Savage S, White W, O'Neill KA. Religious fundamentalism: An empirically derived construct and measurement scale. Arch Religionspsychol 2011; 33(3): 299-323.

[http://dx.doi.org/10.1163/157361211X594159]

[4] Kirkpatrick LA, Hood RW, Hartz G. Fundamentalist religion conceptualized in terms of Rokeach's theory of the open and closed mind: New perspectives on some old ideas. Res Soc Sci Study Relig 1991; 3(1): 157-9.

[5] Laythe B, Finkel D, Kirkpatrick LA. Predicting prejudice from religious fundamentalism and right-wing authoritarianism: A multiple regression approach. J Sci Study Relig 2001; 40(1): 1-10.

[http://dx.doi.org/10.1111/0021-8294.00033]

[6] Rothschild ZK, Abdollahi A, Pyszczynski T. Does peace have a prayer? The effect of mortality salience, compassionate values, and religious fundamentalism on hostility toward out-groups. J Exp Soc Psychol 2009; 45(4): 816-27.

[http://dx.doi.org/10.1016/j.jesp.2009.05.016]

[7] Altemeyer B, Hunsberger B. A revised religious fundamentalism scale: The short and sweet of it. Int J Psychol Relig 2004; 14(1): 47-54.

[http://dx.doi.org/10.1207/s15327582ijpr1401_4]

[8] Fullerton JT, Hunsberger B. A unidimensional measure of Christian orthodoxy. J Sci Study Relig 1982; 21(4): 317-26.

[http://dx.doi.org/10.2307/1385521]

[9] Rowatt WC, Franklin LM. Christian orthodoxy, religious fundamentalism, and right-wing authoritarianism as predictors of implicit racial prejudice. Int J Psychol Relig 2004; 14(2): 125-38. [http://dx.doi.org/10.1207/s15327582ijpr1402_4]

[10] Saroglou V. Religion and the five factors of personality: A metaanalytic review. Pers Individ Dif Res 2002; 32(1): 15-25. [http://dx.doi.org/10.1016/S0191-8869(00)00233-6]

[11] Carlucci L, Albaghli B, Saggino A, Balsamo M. Does a fundamentalist mindset predict a state or trait anxiety? the covariate role of dogmatism. J Relig Health 2020

[http://dx.doi.org/10.1007/s10943-020-01016-5] [PMID: 32279154]

[12] Altemeyer B. Why do religious fundamentalists tend to be prejudiced? Int J Psychol Relig 2003; 13(1): 17-28.

[http://dx.doi.org/10.1207/S15327582IJPR1301_03]

[13] Altemeyer B, Hunsberger B. Fundamentalism and Authoritarianism. Handbook of the Psychology of Religion and Spirituality. New York, NY: Guilford Press 2005; pp. 378-93.

[14] Blogowska J, Saroglou V. Religious fundamentalism and limited prosociality as a function of the target. J Sci Study Relig 2011; 50(1): 44-60.

[http://dx.doi.org/10.1111/j.1468-5906.2010.01551.x]

[15] Mavor KI, Macleod CJ, Boal MJ, Louis WR. Right-wing authoritarianism, fundamentalism and prejudice revisited: Removing suppression and statistical artefact. Pers Individ Dif 2009; 46(5-6): 592-7.

[http://dx.doi.org/10.1016/j.paid.2008.12.016]

[16] Saroglou V, Delpierre V, Dernelle R. Values and religiosity: A metaanalysis of studies using Schwartz's model. Pers Individ Dif Res 2004; 37(4): 721-34.

[http://dx.doi.org/10.1016/j.paid.2003.10.005]

[17] Saroglou V. Religion and psychology of values: "Universals" and Changes. Science and ethics: The axiological contexts of science. Brussels: Peter Lang 2008; pp. 247-72.

[18] Saroglou V, Muñoz García A. Individual differences in religion and spirituality: An issue of personality traits and/or values. J Sci Study
Relig 2008; 47(1): 83-101.

[http://dx.doi.org/10.1111/j.1468-5906.2008.00393.x]

[19] Carlucci L. Fondamentalismo religioso e valori personali: una lettura psicologica. Ric Psicol 2015; 377-89.

[http://dx.doi.org/10.3280/RIP2015-002007]

[20] Lassander M, Nynäs P. Contemporary fundamentalist Christianity in Finland: The variety of religious subjectivities and their association with values. Inter J Rel Trans Con Soc 2016; 2(2): 154-84.

[http://dx.doi.org/10.14220/jrat.2016.2.2.154]

[21] Burris CT, Tarpley WR. Religion as being: Preliminary validation of the Immanence scale. J Res Pers 1998; 32(1): 55-79.

[http://dx.doi.org/10.1006/jrpe.1997.2201]

[22] Tarakeshwar N, Swank AB, Pargament KI, Mahoney A. The sanctification of nature and theological conservatism: A study of opposing religious correlates of environmentalism. Rev Relig Res 2001; 42: 387-404.

[http://dx.doi.org/10.2307/3512131]

[23] Schwartz SH. Universals in the content and structure of values: Theoretical advances and empirical tests in 20 countries. Adv Exp Soc Psychol 1992; 25(1): 1-65.

[http://dx.doi.org/10.1016/S0065-2601(08)60281-6]

[24] Schwartz SH. Basic human values: Theory, measurement, and applications. Rev Fr Sociol 2007; 47(4): 249-88.

[25] Roccas S, Sagiv L, Schwartz SH, Knafo AJP. The big five personality factors and personal values. Pers Soc Psychol Bull 2002; 28(6): 789-801.

[http://dx.doi.org/10.1177/0146167202289008]

[26] Saiz J, Álvaro JL, Martínez I. Relación entre rasgos de personalidad y valores personales en pacientes dependientes de la cocaína. Adicciones $2011 ; 23(2): 125-32$.

[http://dx.doi.org/10.20882/adicciones.155] [PMID: 21647543]

[27] Parks-Leduc L, Feldman G, Bardi A. Personality traits and personal values: A meta-analysis. Pers Soc Psychol Rev 2015; 19(1): 3-29. [http://dx.doi.org/10.1177/1088868314538548] [PMID: 24963077]

[28] Dollinger SJ, Leong FT, Ulicni SK. On traits and values: With special reference to openness to experience. J Res Pers 1996; 30(1): 23-41. [http://dx.doi.org/10.1006/jrpe.1996.0002]

[29] Schwartz S. Value Priorities and Behavior: Applying of Theory of Integrated Value Systems. In: C. Seligman JMO, Zanna MP, Eds. The psychology of values: The Ontario symposium. Hillsdale, NJ: Erlbaum 1996; pp. 1-24.

[30] Proctor SL, McCord DM. Correlates of the openness to experience domain. Individual Differences Res 2009; 7(4): 222-7.

[31] Streyffeler LL, McNally RJ. Fundamentalists and liberals: Personality characteristics of Protestant Christians. Pers Individ Dif Res 1998; 24(4): 579-80.

[http://dx.doi.org/10.1016/S0191-8869(97)00189-X]

[32] Rokeach MT. The open and closed mind: Investigations into the nature of belief systems and personality systems. New York: Basic Books 1960 .

[33] Saroglou V. Beyond dogmatism: The need for closure as related to religion. Ment Health Relig Cult 2002; 5(2): 183-94.

[http://dx.doi.org/10.1080/13674670210144130]

[34] Marty ME, Appleby RS. The Fundamentalism Project. Chicago: University of Chicago Press 1987-1995.

[35] Kellstedt L, Smidt C. Measuring fundamentalism: An analysis of different operational strategies. J Sci Study Relig 1991; 30: 259-78. [http://dx.doi.org/10.2307/1386972]

[36] Platvoet JG, Molendijk ALT. The Pragmatics of Defining Religion: Contexts, Concepts and Contests. Leiden, Boston, Köln: Brill 1999.

[37] Geertz AW. Definition as analytical strategy in the study of religion. Hist Reflect 1999; 25: 445-75.

[38] Schwartz SH, Huismans S. Value priorities and religiosity in four Western religions. Soc Psychol Q 1995; 58: 88-107. [http://dx.doi.org/10.2307/2787148]

[39] Schwartz SH, Melech G, Lehmann A, Burgess S, Harris M, Owens V. Extending the cross-cultural validity of the theory of basic human values with a different method of measurement. J Cross Cult Psychol 2001; 32(5): 519-42.

[http://dx.doi.org/10.1177/0022022101032005001]

[40] Schwartz SH, Rubel T. Sex differences in value priorities: Crosscultural and multimethod studies. J Pers Soc Psychol 2005; 89(6): 1010-28.

[http://dx.doi.org/10.1037/0022-3514.89.6.1010] [PMID: 16393031]

[41] Caprara GV, Barbaranelli C, Pastorelli C, Cervone D. The contribution of self-efficacy beliefs to psychosocial outcomes in adolescence: Predicting beyond global dispositional tendencies. Pers Individ Dif 
2004; 37(4): 751-63.

[http://dx.doi.org/10.1016/j.paid.2003.11.003]

[42] Caprara GV, Barbaranelli C, Borgogni L, Perugini M. The "Big Five Questionnaire": A new questionnaire to assess the five factor model. Pers Individ Dif 1993; 15(3): 281-8.

[http://dx.doi.org/10.1016/0191-8869(93)90218-R]

[43] McCrae RR, Costa PT Jr. Validation of the five-factor model of personality across instruments and observers. J Pers Soc Psychol 1987; 52(1): 81-90.

[http://dx.doi.org/10.1037/0022-3514.52.1.81] [PMID: 3820081]

[44] Carlucci L, Tommasi M, Balsamo M, Furnham A, Saggino A. Religious fundamentalism and psychological well-being: An Italian study. J Psychol Theol 2015; 43(1): 23-33. [http://dx.doi.org/10.1177/009164711504300103]

[45] Carlucci L, Tommasi M, Saggino A. Socio-demographic and five factor model variables as predictors of religious fundamentalism: An italian study. Arch Religionspsychol 2011; 33(2): 253-68. [http://dx.doi.org/10.1163/157361211X576609]

[46] Bengtson VL, et al. Does religiousness increase with age? Age changes and generational differences over 35 years. J Sci Study Relig 2015; 54(2): 363-79.

[http://dx.doi.org/10.1111/jssr.12183]

[47] Moody HR. Is religion good for your health? Gerontologist 2006; 46(1): 147-9.

[http://dx.doi.org/10.1093/geront/46.1.147]

[48] Lewis GJ, Ritchie SJ, Bates TC. The relationship between intelligence and multiple domains of religious belief: Evidence from a large adult US sample. Intelligence $2011 ; 39(6)$ : 468-72.

[http://dx.doi.org/10.1016/j.intell.2011.08.002]

[49] Laythe B, Finkel DG, Bringle RG, Kirkpatrick LA. Religious fundamentalism as a predictor of prejudice: A two-component model. J Sci Study Relig 2002; 41(4): 623-35.

[http://dx.doi.org/10.1111/1468-5906.00142]

[50] Roccas S. Religion and Value Systems J Soc Issues 2005; 61(4): 747-59.

[http://dx.doi.org/10.1111/j.1540-4560.2005.00430.x]

[51] Luk CL, Bond MH. Personality variation and values endorsement in Chinese university students. Pers Individ Dif 1993; 14(3): 429-37. [http://dx.doi.org/10.1016/0191-8869(93)90312-Q]
[52] Hunsberger B, Alisat S, Pancer SM, Pratt M. Religious fundamentalism and religious doubts: Content, connections, and complexity of thinking. Int J Psychol Relig 1996; 6(3): 201-20. [http://dx.doi.org/10.1207/s15327582ijpr0603_7]

[53] Bartoszuk K, Deal JE. Personality, Identity Styles, and Fundamentalism During Emerging Adulthood. Identity 2016; 16(3): 142-53.

[http://dx.doi.org/10.1080/15283488.2016.1190725]

[54] Saroglou V. Religiousness as a cultural adaptation of basic traits: A five-factor model perspective. Pers Soc Psychol Rev 2010; 14(1): $108-25$.

[http://dx.doi.org/10.1177/1088868309352322] [PMID: 20023209]

[55] Higgins ET. Beyond pleasure and pain. Am Psychol 1997; 52(12): 1280-300.

[http://dx.doi.org/10.1037/0003-066X.52.12.1280] [PMID: 9414606]

[56] Webster DM, Kruglanski AW. Individual differences in need for cognitive closure. J Pers Soc Psychol 1994; 67(6): 1049-62.

[http://dx.doi.org/10.1037/0022-3514.67.6.1049] [PMID: 7815301]

[57] Paloutzian RF. Religious conversion and spiritual transformation: A meaning-system analysis.Handbook of the Psychology of Religion and Spirituality. New York, NY: Guilford Press 2005.

[58] Paloutzian RF, Richardson JT, Rambo LR. Religious conversion and personality change. J Pers 1999; 67(6): 1047-79.

[http://dx.doi.org/10.1111/1467-6494.00082]

[59] Saggino A, Carlucci L, Sergi MR, et al. A validation study of the psychometric properties of the Other as Shamer Scale-2. SAGE Open 2017; 7(2)

[http://dx.doi.org/10.1177/2158244017704241]

[60] Carlucci L, D’Ambrosio I, Innamorati M, Saggino A, Balsamo M. Corumination, anxiety, and maladaptive cognitive schemas: When friendship can hurt. Psychol Res Behav Manag 2018; 11: 133-44.

[http://dx.doi.org/10.2147/PRBM.S144907] [PMID: 29692638]

[61] Burris CT, Navara GS. Morality play or playing morality?: Intrinsic religious orientation and socially desirable responding. Self Ident 2002; 1(1): 67-76

[http://dx.doi.org/10.1080/152988602317232812]

[62] Schwartz SH. An overview of the Schwartz theory of basic values. Online Read Psychol Cult 2012; 2(1)

[http://dx.doi.org/10.9707/2307-0919.1116]

\section{(C) 2021 Carlucci et al.}

This is an open access article distributed under the terms of the Creative Commons Attribution 4.0 International Public License (CC-BY 4.0), a copy of which is available at: https://creativecommons.org/licenses/by/4.0/legalcode. This license permits unrestricted use, distribution, and reproduction in any medium, provided the original author and source are credited. 